\title{
Corticosteroid Nonprescription Use: A Cross-Sectional Hospital-Based Study in Basrah
}

\author{
Abbas Ali Mansour ${ }^{a}$ Akream Hussain Odaa $^{b}$ Hameed Laftah Wanoose $^{b}$ \\ Department of Medicine, ${ }^{a}$ Basrah College of Medicine and ${ }^{b}$ Al-Faiha Hospital, Basrah, Iraq
}

\section{Key Words}

Drugs $\cdot$ Self-prescription $\cdot$ Corticosteroids $\cdot$ Iraq

\begin{abstract}
Objective: To study the prevalence and attitude of using nonprescription corticosteroids (oral or parenteral formulation of glucocorticosteroids) in Basrah, Iraq. Methods: A face-to-face model structured interview was used to collect information from 682 patients between January 2006 and December 2008. The following information was obtained: age, gender, marital status, smoking, drinking of alcohol, occupation, educational level, social class and place of residence. Results: Of the 682 (2.6\%) subjects using nonprescription corticosteroids most were females: 471 (69\%); married: 567 (83\%); of low social class: $430(63.1 \%)$; lived in the city center: 475 (69.6\%). The majority $(569,83.5 \%)$ thought that corticosteroid use was safe and 463 (68.0\%) did not feel guilty for using such medications. About half of them (377, $55.3 \%$ ) were still using drugs at the time of presentation. Three hundred and fifty-seven (52.4\%) reported that physicians advised them for the first time to use corticosteroids and the remaining 325 (42.2\%) used it to become beautiful or marry. Three hundred and sixty-four (53.4\%) patients obtained the drug from the pharmacy and 252 (36.9\%) from street vendors. Weight gain was the main indication for use in $342(50.1 \%)$ patients. Almost all had some features of cor-
\end{abstract}

\section{KARGER}

Fax +4161306 1234

E-Mail karger@karger.ch

www.karger.com (c) 2010 S. Karger AG, Basel

1011-7571/10/0193-0182\$26.00/0

Accessible online at:

www.karger.com/mpp ticosteroid side effects. Conclusion: This study showed high use of nonprescription corticosteroid in Basrah, Iraqi. We therefore recommend educational programs to alert the population of the untoward side effects of corticosteroids.

Copyright $\odot 2010$ S. Karger AG, Basel

\section{Introduction}

The Iraqi health system has a lot of problems [1] probably made worse by the United Nations economic sanctions against Iraq in 1990 [2-6]. Self-medication and the use of nonprescription drugs are common in developing countries [7-9].

Because in Iraq medications are not classified as prescription only or over-the-counter drugs, the general public has a wider access to different types of medications than would have been the case. Hence self-medication is a very common habit in Iraq and as such, drugs can be bought in the pharmacy or from street vendors since mid 1980 during the war with Iran and after the economic sanctions took effect in 1991.

The introduction of glucocorticoid therapy by Philip Hench in the 1950s revolutionized the treatment of rheumatic and inflammatory disease [10]. Because of its 'magic effect', it was used indiscriminately without prescription with resultant side effects, which can be very severe 
even if used in low doses [11-14], as has been described in a review article of corticosteroid abuse and/or dependence driven by the euphoria these medications can induce [15].

In many industrialized countries there is a desire to lose weight through dieting or calorie restriction, use of diuretics, vomiting or exercise [16]. However, in many developing countries being fat is culturally acceptable and is associated with beauty, prosperity, health and prestige, and thinness is perceived to be a sign of ill health or poverty [17-19]. We therefore investigated the prevalence and attitude among people in Basrah, in using nonprescription corticosteroids (oral or parenteral formulations of glucocorticosteroid).

\section{Patients and Methods}

An observational, descriptive, cross-sectional study was conducted to estimate the prevalence, attitude and problems of using self-prescribed corticosteroids (oral or parenteral formulations of glucocorticosteroid) among patients attending the outpatient clinic at Al-Faiha Hospital, Basrah, Iraq. This hospital is one of the four major general hospitals in Basrah and as such receives $25 \%$ of outpatient visits from the city districts.

A face-to-face model structured interview over 3 years from January 2006 to December 2008 was used. Information on age, sex, marital status, smoking, drinking of alcohol, occupation, educational level, social class and place of residence was obtained by specially trained physicians. The interview was done only for those who had obvious features of corticosteroid side effects or those who admitted that they were using self-prescription corticosteroids whether or not there were any features of side effects. Subjects who smoked at least one cigarette per day or drank alcohol once during the year before the examination were classified as smokers or drinkers accordingly. Socioeconomic status, based on family income and educational level [20], was used to determine the patient's social class.

Inclusion criteria were: corticosteroid use without medical advice; continued use after short prescription regardless of the duration; patients who denied using corticosteroids, but had clinical features of hypercortisolism upon clinical examination. The name and type of corticosteroid were suggested by the patients according to formulation type and color in most of the cases. None of our patients gave the duration of steroid use exactly. Patients who were using prescribed corticosteroids regardless of the duration or side effects such as asthma, nephrotic syndrome, chronic immune thrombocytopenia, rheumatoid arthritis were excluded from the study.

The nonprescription corticosteroids included oral prednisolone, dexamethasone tablets, injection solution and syrup commonly combined with cyproheptadine. The injection solutions were methylprednisolone acetate, betamethasone acetate, triamcinolone acetate or a combination. Depot corticosteroid was used monthly while short-acting corticosteroid injections such as dexamethasone or betamethasone were used daily. A formulation widely used contained dexamethasone and antihistamine (hya- nil). Some patients were reluctant to disclose the use of corticosteroid but did so when confronted with the physical signs of steroid side effects.

Body mass index (BMI) was calculated as body weight in kilograms divided by the squared value of body height in meters $(\mathrm{kg} /$ $\mathrm{m}^{2}$ ). Three blood pressure measurements were obtained by physicians. The measurements were made with the patient in a sitting position after $5 \mathrm{~min}$ of rest. Hypertension was defined as self-reported use of antihypertensive medication within the past 2 weeks or an average blood pressure of $\geq 140 \mathrm{~mm} \mathrm{Hg}$, or an average diastolic blood pressure of $\geq 90 \mathrm{~mm} \mathrm{Hg}$, or both. Type 2 diabetes mellitus was diagnosed according to the American Diabetes Association criteria of fasting plasma glucose value $\geq 126 \mathrm{mg} / \mathrm{dl}$ ( $7 \mathrm{mmol} / \mathrm{l}$ ) on two occasions or symptoms of diabetes and a casual plasma glucose $\geq 200 \mathrm{mg} / \mathrm{dl}(11.1 \mathrm{mmol} / \mathrm{l})$ or history of diabetes [21].

The questions included knowledge of adverse effects of corticosteroids; guilty feeling for using nonprescription drugs; duration of use; on whose advice they first used corticosteroids; source of drug; any other first-degree family members using corticosteroids at any time previously. They were later asked why they were using corticosteroids. Then they were examined for any features of corticosteroid side effects. The features of side effects as published in the literature and fungal skin infections were dermatophytosis, candidiasis and pityriasis versicolor [10,22].

Prescription drug misuse/abuse for the purpose of this study was defined as the use or illicit purchase of prescription corticosteroids by somebody for whom they were not prescribed, or where people used prescription corticosteroids in a way that they were not intended (e.g. for weight gain effects) or where such corticosteroids are sold on the illicit market.

Written informed consent was obtained from all subjects prior to enrollment. Patients' characteristics were reported as percentages or mean \pm standard deviation (SD).

\section{Results}

Of 25,968 patients seen in the medical outpatient clinic over 3 years, $682(2.6 \%)$ were using corticosteroids without prescriptions. Their mean age was $39.6 \pm 14.1$ years (range 15-96). Of the 682 patients, 471 (69\%) were females, 567 (83\%) were married (including divorcees and widows), 457 (67\%) unemployed or housewives, 32 (4.6\%) policemen, 7 (1\%) paramedics, $90(13.1 \%)$ smokers, 7 (1.0\%) alcohol drinkers and $63.1 \%$ were from a low social class (table 1). The school achievement was $5.82 \pm 5.1$ years. Four hundred and seventy-five (69.6\%) were from the city center (of whom $90 \%$ were from Heanea, Al-Hadi and Gezeasa, which are the poorest areas in Basrah). Mean BMI was $25.8 \pm 5.8 \mathrm{~kg} / \mathrm{m}^{2} ; 415(60.8 \%)$ were either overweight or obese (BMI $\geq 25 \mathrm{~kg} / \mathrm{m}^{2}$ ).

Misbeliefs and attitudes towards the use of corticosteroids are presented in table 2 . Five hundred and ninetysix (83.5\%) thought that corticosteroid use was safe and 
Table 1. Study sample characteristics (682 patients)

\begin{tabular}{|c|c|}
\hline & $\mathrm{n}(\%)$ \\
\hline \multicolumn{2}{|l|}{ Gender } \\
\hline Male & $211(30.9)$ \\
\hline Female & $471(69.0)$ \\
\hline \multicolumn{2}{|l|}{ Marital state } \\
\hline Married $^{1}$ & $567(83.0)$ \\
\hline Smokers & $90(13.1)$ \\
\hline Alcohol drinkers & $7(1.0)$ \\
\hline \multicolumn{2}{|l|}{ Occupation } \\
\hline Employed & $152(22.2)$ \\
\hline Teacher & $19(2.7)$ \\
\hline Student & $15(2.1)$ \\
\hline Policeman & $32(4.6)$ \\
\hline Paramedic & $7(1.0)$ \\
\hline Housewife ${ }^{2}$ & $457(67.0)$ \\
\hline Qualification, years of school achievement & $5.82 \pm 5.1$ \\
\hline \multicolumn{2}{|l|}{ Social class } \\
\hline Low & $430(63.0)$ \\
\hline Medium & $244(35.7)$ \\
\hline High & $6(0.8)$ \\
\hline \multicolumn{2}{|l|}{ Residency } \\
\hline City center ${ }^{3}$ & $475(69.6)$ \\
\hline Al-Zubair & $60(8.8)$ \\
\hline Al-Midaina & $24(3.5)$ \\
\hline Al-Qurna & $39(5.7)$ \\
\hline Al-Faw & $2(0.3)$ \\
\hline Outside & $48(7.0)$ \\
\hline Shatt Al-Arab & $19(2.8)$ \\
\hline Abu Al-Khaseeb & $15(2.2)$ \\
\hline Mean weight $\pm S D, k g$ & $69.8 \pm 15.9$ \\
\hline \multicolumn{2}{|l|}{$\mathrm{BMI}, \mathrm{kg} / \mathrm{m}^{2}$} \\
\hline Mean $\pm S D$ & $25.8 \pm 5.8$ \\
\hline$<18.5$ & $40(5.8)$ \\
\hline $18.5-<25$ & $227(33.2)$ \\
\hline$\geq 25$ & $415(60.8)$ \\
\hline $\begin{array}{l}{ }^{1} \text { Includes widowed, divorced. } \\
2 \text { Includes unemployed and retired. } \\
{ }^{3} \text { City center }(90 \% \text { from Heanea, Al-Ha }\end{array}$ & i and Gezeasa). \\
\hline
\end{tabular}

$463(68.0 \%)$ did not feel guilty using such medications. Mean duration of use was $3.7 \pm 3.5$ years and 377 (55.3\%) were still using the drug at the time of the study. Those who stopped using drugs usually did so suddenly without medical advice. The exact date of starting using self-prescription corticosteroids was difficult to ascertain, but most of them claimed that they did not use them before 1990.

Three hundred and fifty-seven (52.4\%) patients claimed that they used corticosteroids for the first time based on advice of a physician, while 288 (42.2\%) used
Table 2. Misbeliefs and attitudes towards the use of corticosteroids

n $(\%)$

Is steroid use safe?

Yes $\quad 569(83.5)$

No $113(16.5)$

Do you feel guilty?

Yes $219(32.0)$

No $463(68.0)$

Duration of use, years $\quad 3.7 \pm 3.5$

Stopped

Yes $308(45.2)$

No 374 (54.8)

Who advised you to start corticosteroids?

Doctor

$357(52.3)$

Herself to become beautiful or marry $288(42.2)$

Spouse $19(2.7)$

Sister $12(1.7)$

Mother $6(0.8)$

Source of corticosteroids

Pharmacy 364 (53.4)

Street vendors $251(36.9)$

Nursing staff 67 (9.7)

Family history of corticosteroid use ${ }^{1} \quad 256(40)$

Addiction of other drugs $^{2} \quad 4(0.5)$

${ }^{1}$ First-degree relatives.

${ }^{2}$ All males.

them on themselves to become beautiful or marry. Three hundred and sixty-four (53.4\%) obtained the drug from the pharmacy and 251 (36.9\%) from street vendors. Two hundred and fifty-six (40\%) had first-degree relatives who used corticosteroids and $7(0.6 \%)$ concurrently used other drugs.

Self-reported indications of corticosteroid use are given in table 3 . Weight gain was the main indication for use in 342 (50.1\%), followed by asthma (144, 21.1\%). In the weight gain group, dexamethasone was the commonest formulation used in 290 (84.8\%), followed by oral prednisolone in 26 (7.6\%). In the asthma group, prednisolone was most common in $74(51.4 \%)$ and dexamethasone in 43 (29.9\%), while in the allergy (nonspecific) group 67.1\% were using dexamethasone and $52.2 \%$ of the joint pain group were using methylprednisolone acetate.

The main features of corticosteroid abuse are listed in table 4. Thin skin was seen almost always in all patients. Moon face, striae and malaise/fatigue were seen in 92.0, 51.4 and $48.3 \%$, respectively. Buffalo hump, central obesity, and supraclavicular fat pad were seen in $46.4,45.4$ 
Table 3. Self-reported indication of corticosteroids according to formulation

\begin{tabular}{|c|c|c|c|c|c|c|}
\hline & $\begin{array}{l}\text { Total, } \\
\text { n (\%) }\end{array}$ & $\begin{array}{l}\text { Dexamethasone }{ }^{1} \text {, } \\
\mathrm{n}(\%)\end{array}$ & $\begin{array}{l}\text { Prednisolone, } \\
\text { n (\%) }\end{array}$ & $\begin{array}{l}\text { Methylpredniso- } \\
\text { lone acetate, } \mathrm{n}(\%)\end{array}$ & $\begin{array}{l}\text { Betamethasone } \\
\text { acetate, } \mathrm{n}(\%)\end{array}$ & $\begin{array}{l}\text { Triamcinolone } \\
\text { acetate, } \mathrm{n}(\%)\end{array}$ \\
\hline Weight gain & $342(50.1)$ & $290(84.8)$ & $26(7.6)$ & $15(4.4)$ & $8(2.3)$ & $3(0.9)$ \\
\hline Allergy (nonspecific) ${ }^{2}$ & $143(20.9)$ & $96(67.1)$ & $15(10.5)$ & $17(11.9)$ & $11(7.7)$ & $4(2.8)$ \\
\hline Joint pain & $23(3.3)$ & $5(21.7)$ & $3(13.0)$ & $12(52.2)$ & $2(8.7)$ & $1(4.3)$ \\
\hline Rheumatoid arthritis & $14(2.0)$ & $2(14.3)$ & $11(78.6)$ & $1(7.1)$ & $0(0.0)$ & $0(0.0)$ \\
\hline Total & $682(100.0)$ & $438(64.2)$ & $139(20.4)$ & $63(9.2)$ & $31(4.5)$ & $11(1.6)$ \\
\hline
\end{tabular}

\footnotetext{
${ }^{1}$ More than one type used by some and different routes of administration including oral tablets, syrup and injections.

2 Allergy includes eyes, nose, cough, dyspnea and skin including urticaria and itching.

${ }^{3}$ Includes 4 cases of Behçet's disease, 1 ulcerative colitis, 2 peripheral neuropathy, 2 nephrotic syndrome, 3 immune thrombocytopenic purpura, 3 obstructive airway disease, and 1 hair fall.
}

Table 4. Symptoms and signs of corticosteroid abuse and complications $^{1}$

\begin{tabular}{ll}
\hline Symptoms and signs & $\mathrm{n}(\%)$ \\
\hline Thin skin & $682(100.0)$ \\
Moon face & $628(92.0)$ \\
Striae & $351(51.4)$ \\
Malaise/fatigue & $330(48.3)$ \\
Buffalo hump & $317(46.4)$ \\
Central obesity & $310(45.4)$ \\
Supraclavicular fat pad & $278(40.7)$ \\
Diabetes mellitus & $121(17.7)$ \\
Addisonian crisis & $105(15.3)$ \\
Whole-body obesity & $99(14.5)$ \\
Hypertension & $80(11.7)$ \\
Fungal skin infection & $66(9.6)$ \\
Cataract & $59(8.6)$ \\
Glaucoma & $6(0.8)$ \\
Other features & $59(8.6)$ \\
\hline
\end{tabular}

\footnotetext{
${ }^{1}$ Patients may have more than one feature.

${ }^{2}$ Because most of those who stopped it did that suddenly.

${ }^{3}$ Repeated vomiting, severe hyperemesis gravidarum.
}

and $40.7 \%$, respectively. Diabetes mellitus was seen in $17.7 \%$ (all patients admitted that their diabetes began after they started corticosteroids and some of them had presenting symptoms of diabetes for the first time) and $15.3 \%$ presented with addisonian crisis. Whole-body obesity was seen in $14.5 \%$ and hypertension in $11.7 \%$. Fungal skin infection was seen in $9.6 \%$ and cataract in $8.6 \%$.

\section{Discussion}

Most of our patients were married females and unemployed or housewives. The majority were from a low social class, the poorest part of the city center and either had normal weight or were overweight.

In spite of the known side effects, most of the people (83.5\%) thought that corticosteroid use was safe and as such did not feel guilty for using such medication. They had been using it for long periods of time and more than half were still using them during the study period. Approximately half $(52.3 \%)$ claimed they used the drug for the first time based on physician's advice, followed by the patients themselves to become fat, beautiful and marry (however this was difficult to ascertain because it was unlikely that a physician would prescribe these dangerous drugs for weight gain). It seems that previous prescriptions could have served as the basis for subsequent self-medication. Most common sources of drugs were pharmacies or street vendors and less than half of them have a first-degree relative using corticosteroids. The most frequently cited reason for self-medicating was to gain weight and subjects used mostly dexamethasone followed by oral prednisolone, which is consistent with a previous study done in Morocco [23].

In a clinical study on the misuse of topical corticosteroids in Teaching Hospitals in Al-Najaf in Iraq for the period 2001-2002, 7.9\% had misused topical corticosteroids. About half were aged 10-19 years. Potent and highly potent preparations were the most commonly used. In $34.3 \%$ of cases, medical staff were responsible for pre- 
scribing/recommending the drugs [12]. Before their first visit to a specialized department in México, nearly two thirds of rheumatologic patients had taken glucocorticoids, which in most cases resulted from inappropriate prescriptions or recommendations by general physicians, specialists other than rheumatologists, and lay people [11].

Reported self-medication is common practice in $42.5 \%$ of Jordanians [7], 59\% of Nepalese [8] and $83 \%$ of patients attending an ENT clinic in Brazil [9], but none of them used corticosteroids [7-9]. Among first-year medical students of the Arabian Gulf University in Bahrain, the practice of self-medication was common and often inappropriate [24], as also observed among adolescents in Kuwait [25].

Most of our patients had developed side effect of corticosteroids, such as thin skin, moon face and presented with addisonian crisis or had diabetes mellitus and complications of drug use. Steroid-induced diabetes had been observed in 5 of 110 patients with arthritis and related disorders, treated by physicians in Pakistan [13].

Some patients in this study presented with addisonian crisis (15.3\%) that was accompanied by vomiting and abdominal pain. Endoscopy was not helpful to make the diagnosis. Many patients, especially women, did not inform family members that they were using corticosteroids. Failure to acknowledge use of corticosteroids and withholding such information from attending physicians could lead to a missed diagnosis. It has been established that exogenous corticosteroid therapy suppresses the production of corticotropin-releasing hormone and corticotropin and can induce adrenal atrophy that may persist for months after the cessation of corticosteroid treatment and could prove fatal during stress $[26,27]$.

We have a sizable percentage of subjects that use corticosteroids at night only, in which cases they have severe adrenal suppression. Equally important, this study confirmed the previous suggestion [28] that appropriate governmental regulations and inspections are needed to improve the health care system in Iraq.

\section{Limitations}

There could have been patients who were using these medications but had not yet developed physical signs and therefore were not included in the study if they denied using corticosteroids. Furthermore, this study could have underestimated corticosteroid nonprescription use in the community especially among poor people, because the study was hospital-based.

\section{Conclusion}

This study showed high use of nonprescription corticosteroids in Basrah, Iraq. We therefore recommend appropriate educational programs to alert the population of the untoward side effects of corticosteroids.

\section{References}

1 Alwan AD: Health-sector funding: options for funding health care in Iraq. East Mediterr Health J 2008; 14:1372-1379.

- 2 Frangoul H, Al-Jadiry MF, Shyr Y, Ye F, Shakhtour B, Al-Hadad SA: Shortage of chemotherapeutic agents in Iraq and outcome of childhood acute lymphocytic leukemia, 1990-2002. N Engl J Med 2008;359:435437.

-3 Mansour AA, Wanoose HL: Insulin crisis in Iraq. Lancet 2007;369:1860.

4 Wolfenden L, Wiggers J: Addressing the health costs of the Iraq war: the role of health organisations. Med J Aust 2007;186:380381.

5 United Nations Assistance Mission for Iraq: Human rights report. 1 July-31 August 2006 (accessed Nov 2006).

6 Al Sheibani BI, Hadi NR, Hasoon T: Iraq lacks facilities and expertise in emergency medicine. BMJ 2006;333:847.
7 Shankar PR, Partha P, Shenoy N: Self-medication and non-doctor prescription practices in Pokhara valley, Western Nepal: a questionnaire-based study. BMC Fam Pract 2002; $3: 17$.

$\checkmark 8$ Yousef AM, Al-Bakri AG, Bustanji Y, Wazaify M: Self-medication patterns in Amman, Jordan. Pharm World Sci 2008;30:2430.

9 Servidoni AB, Coelho L, Navarro Mde L, de Avila FG, Mezzalira R: Self-medication profile of ENT patients. Braz J Otorhinolaryngol 2006; $72: 83-88$

10 McDonough AK, Curtis JR, Saag KG: The epidemiology of glucocorticoid-associated adverse events. Curr Opin Rheumatol 2008; 20:131-137.
11 Alvarez-Hernández E, Vázquez-Mellado J, Casasola-Vargas JC, Moctezuma-Ríos JF, García-García C, Medrano-Ramírez G, et al: The use of glucocorticoids by rheumatologic patients before attending a specialized department in México. J Clin Rheumatol 2008; 14:148-152.

12 Al-Dhalimi MA, Aljawahiry N: Misuse of topical corticosteroids: a clinical study in an Iraqi hospital. East Mediterr Health J 2006; 12:847-852.

$\checkmark 13$ Farooqi AZ, Nasir-ud-Din, Aman R, Qamar T, Aziz S: Corticosteroid use and abuse by medical practitioners for arthritis and related disorders in Pakistan. Br J Rheumatol 1997;36:91-94.

14 Keenan GF: Management of complications of glucocorticoid therapy. Clin Chest Med 1997; 18:507-520.

15 Warrington TP, Bostwick JM: Psychiatric adverse effects of corticosteroids. Mayo Clin Proc 2006;81:1361-1367. 
16 Wardle J, Griffith J: Socioeconomic status and weight control practices in British adults. J Epidemiol Community Health 2001;55: 185-190.

17 Brown PJ: Culture and the evolution of obesity. Hum Nat 1991;2:31-57.

- 18 Treloar C, Porteous J, Hassan F, Kasniyah N, Lakshmanudu M, Sama M, Sja'bani M, Heller RF: The cross cultural context of obesity: an INCLEN multicentre collaborative study. Health Place 1999;5:279-286.

19 Pollock NJ: Cultural elaborations of obesity: fattening practices in Pacific societies. Asia Pac J Clin Nutr 1995;4:357-360.
20 Park JE, Oark K: Textbook of Preventive and Social Medicine, ed 4. Jabalpur, Banarsidas Bahanot, 1985, pp 25-26.

21 American Diabetic Association: Report of the expert committee on the diagnosis and classification of diabetes mellitus. Diabetes Care 2003;26(suppl 1):S5-S20.

22 Curtis JR, Westfall AO, Allison J, Bijlsma JW, Freeman A, George V, Kovac SH, Spettell CM, Saag KG: Population-based assessment of adverse events associated with long-term glucocorticoid use. Arthritis Rheum 2006; 55:420-426.

23 Rguibi M, Belahsen R: Fattening practices among Moroccan Saharawi women. East Mediterr Health J 2006;12:619-624.

24 James H, Handu SS, Al Khaja KA, Otoom S, Sequeira RP: Evaluation of the knowledge, attitude and practice of self-medication among first-year medical students. Med Princ Pract 2006;15:270-275.
25 Abahussain E, Matowe LK, Nicholls PJ: Selfreported medication use among adolescents in Kuwait. Med Princ Pract 2005; 14:161164.

26 Cooper MS, Stewart PM: Corticosteroid insufficiency in acutely ill patients. N Engl J Med 2003;348:727-734.

27 Ledingham IM, Watt I: Influence of sedation on mortality in critically ill multiple trauma patients. Lancet 1983;i:1270.

28 Dyer O: Iraqi healthcare system still crippled five years after invasion, says report. BMJ 2008;336:113. 